\title{
Creatina: auxílio ergogênico com potencial antioxidante?
}

\section{Creatine: ergogenic aid with antioxidant potential?}

Tácito Pessoa de SOUZA JUNIOR ${ }^{1}$

Benedito PEREIRA2

\section{R E S U M O}

A creatina é largamente utilizada como auxilio ergogênico, com algumas evidências quanto ao seu efeito positivo na massa magra, força/potência e resistência muscular. Entretanto, esses estudos não conseguiram identificar potenciais mecanismos bioquímicos que pudessem explicar seu efeito na fadiga ou turnover de proteína muscular, existindo a possibilidade de que alguns indivíduos não sejam responsivos a esse suplemento. Outro possível efeito da creatina, que vem sendo recentemente investigado, é a sua ação antioxidante. Mesmo com poucos trabalhos disponíveis, duas possibilidades existem para explicar esse efeito: 1) Ação indireta como tampão energético, devido ao aumento na concentração tecidual de fosfocreatina, que favoreceria a menor produção de metabólitos do ciclo de degradação de purinas (ciclo de Lowenstein), resultando em queda na formação de hipoxantina, xantina e ácido úrico, assim como em espécies reativas de oxigênio (superóxido, peróxido de hidrogênio e radical hidroxil); 2) Por ação direta, apesar de essa propriedade ser inferior à dos antioxidantes já bem conhecidos, como a glutationa reduzida. Mesmo assim, poderia atuar conjuntamente com estes. O objetivo desta comunicação é relatar dados disponíveis sobre esses dois itens.

Indexing terms: Exercício. Estresse oxidativo. Metabolismo. Creatina.

A B S T R A C T

Creatine is largely used as an ergogenic aid with some evidence regarding its positive effect on lean body mass, strength/power and muscle endurance. However, most studies were not capable of identifying biochemical mechanisms that could explain its effect on fatigue or muscle protein turnover. There is also the possibility that some individuals are non-responsive to this supplement. Another possible effect of creatine that has been recently investigated is its antioxidant action, but few studies explored this subject. Nonetheless, it can be emphasized that the antioxidant effect of creatine works in the organism in the following way: 1) Indirect action as an energy buffer, due to the increase in muscle phosphocreatine concentrations which would favor a reduced production of metabolites of the purine nucleotide cycle (cycle of Lowenstein) and, as a consequence, a drop in the production of hypoxanthine, xanthine, uric acid, and reactive oxygen species; 2) Direct action (a less powerful action when compared with known antioxidants, such as reduced glutathione). Yet, it could still work in association with them. The objective of this work is to review the available data on the two abovementioned mechanisms.

Indexing terms: Exercise. Oxidative stress. Supplementation. Metabolism. Creatine.

${ }^{1}$ Universidade Metropolitana de Santos, Faculdade de Educação Física de Santos. Santos, SP, Brasil.

2 Universidade de São Paulo, Escola de Educação Física e Esporte, Departamento de Esporte. Av. Prof. Melo Moraes, 65, 05508-900, São Paulo, SP. Correspondência para/Correspondence to: B. PEREIRA. E-mail: <benepe@usp.br>. 


\section{N T R O D U ÇÃ O}

Em associação ao seu reconhecido papel como auxílio ergogênico' em exercícios intensos de curta duração, pesquisas recentes têm demonstrado que a creatina também possui propriedades antioxidantes². Existem duas explicações possíveis para esse efeito, que são: 1) Ação indireta como tampão energético, devido ao aumento na concentração tecidual de fosfocreatina, que pode favorecer a menor produção de intermediários da degradação da adenosina trifosfato (ATP), principalmente no ciclo de degradação de purinas ${ }^{3}$ e; 2) Ação direta, devido à presença de arginina em sua estrutura molecular².

O objetivo desta comunicação é mostrar, a partir de dados deste grupo de pesquisadores $\mathrm{e}^{4}$ de outros autores ${ }^{2,5}$ a possível contribuição antioxidante da creatina durante a realização de exercício físico. Este tema é de relevante para a nutrição e a bioquímica do exercício, uma vez que há poucas referências na literatura, mas com dados promissores. Pretende-se, assim, estimular o desenvolvimento de pesquisas em torno desta temática.

Durante a realização de treinamento físico intenso ou na exigência física máxima, há maior formação intramuscular de ânion radical superóxido $\left(\mathrm{O}_{2}^{*}\right)$, peróxido de hidrogênio $\left(\mathrm{H}_{2} \mathrm{O}_{2}\right)$ e radical hidroxil $\left(\bullet^{\circ} \mathrm{OH}\right)$, dentre outros, denominados por espécies reativas de oxigênio $\left(\mathrm{O}_{2}\right)$, resultando em lesões oxidativas celulares e teciduais acima do normal nessas condições ${ }^{4,6}$. Para proteger contra essas lesões, as células possuem antioxidantes químicos e enzimáticos, existindo evidências de que isso não é suficiente para as proteger durante o exercício físico intenso ${ }^{7}$. Embora haja algumas restrições quanto ao seu consumo pela Sociedade Brasileira de Medicina do Esporte, a creatina não se encontra na lista atual de substâncias proibidas pela World Anti-Doping Agengy (WADA). Além disso, alguns estudos, como os realizados por Schilling et al. ${ }^{8}$, Persky \& Brazeau ${ }^{9}$, Ellis \& Rosenfeld, com indivíduos saudáveis, não reportaram efeitos colaterais nas funções renais, gastrointestinais e hepáticas com a suplementação oral de creatina. Ressalta-se que não se pretende com isso estimular seu consumo em associação à prática esportiva, mas relatar uma importante propriedade química exibida por esta molécula, no sentido de incentivar pesquisas sobre o tema.

\section{Creatina como antioxidante}

A molécula de ATP é a fonte imediata de energia para a contração muscular e os demais processos dela dependentes. Contudo, sua concentração intramuscular é muito baixa, fazendo com que vias alternativas de sua regeneração sejam imediatamente ativadas devido ao seu consumo. Para tanto, é fornecido poder redutor de carboidratos e lipídeos. Esse processo é lento, comparativamente à utilização da fosfocreatina, sendo, em função disso, muito importante na regeneração da ATP em atividades físicas intensas e de curta duração. Com a intensificação da utilização de fosfocreatina e de ATP pela fibra muscular durante esse tipo de exercício, ocorre ativação simultânea do ciclo de degradação de purinas (ciclo de Lowenstein), devido ao aumento na concentração intramuscular de adenosina monofosfato (AMP). As principais conseqüências da ativação dessa via são a produção paralela de amônia, hipoxantina, xantina, urato e de espécies reativas de oxigênio ${ }^{11,12}$.

Estudos realizados com suplementação de creatina previamente ao exercício intenso resultaram em queda, tanto na produção de amônia como na de hipoxantina ${ }^{13}$. Portanto, é possível que o aumento nos estoques intracelulares de creatina pelo treinamento físico, ou seu consumo adicional previamente à realização do exercício intenso, possa servir como antioxidante indireto. Ou seja, a menor produção de hipoxantina em decorrência de tal procedimento, assim como devido à redução paralela de seu catabolismo em xantina e urato, poderia resultar em menor produção de espécies reativas de oxigênio na fibra muscular durante o exercício físico ${ }^{14}$. 
A creatina é constituída pelos aminoácidos glicina e arginina, que sofrem ação da enzima glicina amidiltransferase, resultando em guanidinoacetato e ornitina. Por sua vez, a ornitina sofre ação da enzima guanidinoacetato metiltransferase, participando, além disso, como substrato da enzima óxido nítrico sintase e resultando na formação de óxido nítrico ${ }^{15}$. Ressalta-se que o óxido nítrico é um radical livre que modula o metabolismo, a contratilidade e o consumo de glicose no músculo esquelético e participa do ciclo da uréia, além de poder reagir com $\mathrm{O}_{2}{ }^{*-}$ e gerar peroxinitrito (OONO-).

A arginina protege células endoteliais contra lesões oxidativas causadas por lipoproteínas (LDL) oxidadas ${ }^{16}$. Dados adicionais mostram que a arginina pode neutralizar $\mathrm{O}_{2}{ }^{\circ}$, levando à sugestão de que a creatina pode também exercer efeito antioxidante direto, além de indireto. Lawler et al. ${ }^{2}$ e Sestili et. al. ${ }^{5}$ obtiveram resultados a favor dessa hipótese. Por exemplo, a creatina demonstrou capacidade de remover ácido 2,2'azino-bis (3-etilbenzenotiazolino-6-sulfônico (ABTS+), $\mathrm{O}_{2}{ }^{*-}$ e OONO. Por outro lado, a creatina não foi capaz de neutralizar de maneira significativa $\mathrm{H}_{2} \mathrm{O}_{2}$ e t-butilhidroperóxido (tB-OOH).

Esses dados demonstram que a creatina exerce efeito antioxidante claramente seletivo. Por fim, sua ação antioxidante contra ABTS+ é significativamente inferior à da glutationa reduzida, mas potencializa sua ação. Pode-se concluir, em função dos resultados de Lawler et al. ${ }^{2}$, que a ação antioxidante direta da creatina parece se limitar a radicais livres ou a espécies reativas de oxigênio iônicas. Além disso, como a creatina exerce efeito antioxidante inferior ao da glutationa reduzida e demonstra efeito aditivo, quando na sua presença, é possível que funcione como suporte aos antioxidantes mais potentes.

Essa função se torna relevante, principalmente porque a creatina se encontra no sarcoplasma, podendo proteger suas estruturas contra oxidação por espécies reativas de oxigênio durante o exercício físico, como, por exemplo, proteínas importantes na regulação metabólica, e atenuar o aparecimento da fadiga ou favorecer a recupe- ração após o exercício. Quanto a isso, mesmo que existam resultados controversos, antioxidantes químicos reduzem o ponto de fadiga em animais durante o exercício físico intenso ${ }^{4,6}$. Esses dados podem ser controversos em razão dos diferentes tipos de animais estudados, de controle nutricional deficiente ou de tipo do exercício praticado ${ }^{17}$. Além disso, o estresse oxidativo devido ao aumento na produção de oxidantes ou à falta de antioxidantes, aumenta a oxidação de proteínas, assim como a sua degradação ${ }^{11,12}$.

Outros estudos demonstraram que a creatina exerce efeitos protetores em uma grande variedade de doenças em que o estresse oxidativo encontra-se envolvido ${ }^{18}$. Além disso, efeitos protetores antioxidantes diretos da creatina, em estratos de células normais ou sob estresse oxidativo, também foram identificados ${ }^{5}$. Nestes estudos foram utilizadas as seguintes células em culturas expostas a oxidantes: promonócitos (U937), células endoteliais (HUVEC) e mioblastos (C2C12) expostos a $\mathrm{H}_{2} \mathrm{O}_{2}, \mathrm{tB}-\mathrm{OOH}$ e, no caso das células U937, também peroxinitrito. A creatina (0,1-10 mM) atenuou os efeitos citotóxicos causados por oxidantes em todas as células estudadas, sendo que a proteção foi, invariavelmente, associada com a elevação da fração intracelular de creatina, mas não com valores de fosfocreatina. Foi ainda verificado que a creatina não afetou as atividades das enzimas catalase e glutationa peroxidase, mas preveniu o consumo de grupos sulfidrílicos do pool não protéico em células U937 e HUVEC.

A partir de espectroscopia de massa se demonstrou que moléculas com 136 Dalton de peso molecular, que representam produtos oxidados de creatina, formaram-se em reações tamponadas contendo creatina na presença de $\mathrm{H}_{2} \mathrm{O}_{2}$, assim como em extratos de células tratadas com $\mathrm{H}_{2} \mathrm{O}_{2}$ ou tB-OOH previamente suplementadas com creatina. Finalmente, a citoproteção exercida pela creatina nesses experimentos parece não estar relacionada com a quelação de ferro, como demonstrado por alguns autores ${ }^{5}$. Os mesmos autores concluem que a creatina exerce efeito antioxidante moderado em células, porém signi- 
352 | T.P. SOUZA JUNIOR \& B. PEREIRA

ficante, dependendo se as espécies químicas são derivadas do oxigênio ou do nitrogênio.

Em trabalhos recentemente publicados foram demonstradas atenuações nos valores de quimioluminescência urinária, um possível indicador de estresse oxidativo, em função da suplementação de creatina associada ao treinamento de força/hipertrofia e a corridas com longa duração ${ }^{4,6}$. Os dados descritos nesses trabalhos sugerem que esse efeito pode estar relacionado com ação direta e/ou indireta exercida pela creatina suplementada. Destaca-se que sua função antioxidante também não se mostrou totalmente eficiente, já que os valores obtidos na quimioluminescência urinária não foram totalmente neutralizados.

\section{CONSIDERAÇÕ ES FINAIS}

A creatina é um viável agente ergogênico com papel antioxidante indireto, devido ao seu efeito atenuador da formação de produtos de degradação de purinas. Além disso, existem evidências de que seu papel antioxidante direto é moderado, comparado com antioxidantes mais potentes (glutationa reduzida). Sua ação antioxidante indireta foi evidenciada por estudos que demonstraram menor produção de hipoxantina, xantina e ácido úrico após suplementação com creatina. Investigações encontram-se em andamento no sentido de comprovar os efeitos indiretos antioxidantes da creatina tanto in vitro como in vivo.

\section{COLABORADORES}

T.P. SOUZA JUNIOR e B. PEREIRA participaram da elaboração de estratégia experimental, da coleta de dados, da tabulação, da discussão dos resultados e da elaboração do artigo.

\section{REFERÊ NCIAS}

1. Bemben MG, Lamont HS. Creatine supplementation and exercise performance: recent findings. Sports Med. 2005; 35(2):107-25.
2. Lawler JM, Barnes WS, Wu G, Song W, Demaree S. Direct antioxidant properties of creatine. Biochem Biophys Res Commun. 2002; 290(1):47-52.

3. Francaux M, Demeure R, Goudemant JF, Poortmans JR. Effect of exogenous creatine supplementation on muscle PCr metabolism. Int J Sports Med. 2000; 21(2):139-45.

4. Souza Junior T, Oliveira P, Pereira B. Exercício Físico e estresse oxidativo: efeitos do exercício físico intenso sobre a quimioluminescência urinária e malondialdeído plasmático. Rev Bras Med Esporte. 2005;11(1):91-96.

5. Sestili P, Martinelli C, Bravi G, Piccoli G, Curci R, Battistelli $M$, et al. Creatine supplementation affords cytoprotection in oxidatively injured cultured mammalian cells via direct antioxidant activity. Free Radic Biol Med. 2006; 40(5):837-49.

6. Souza Junior T, Pereira B, Oliveira P. Efeitos da suplementação com $\mathrm{CrH} 2 \mathrm{O}$ sobre a quimioluminescência urinária em universitários submetidos a 8 semanas de treinamento de força. Conexões. 2005; 3(2):170-80.

7. Pereira B, Costa Rosa LF, Safi DA, Medeiros MH, Curi R, Bechara EJ. Superoxide dismutase, catalase, and glutathione peroxidase activities in muscle and lymphoid organs of sedentary and exercise-trained rats. Physiol Behav. 1994; 56(5):1095-9.

8. Schilling BK, Stone MH, Utter A, Kearney JT, Johnson M, Coglianese R, et al. Creatine supplementation and health variables: a retrospective study. Med Sci Sports Exerc. 2001; 33(2):183-8.

9. Persky AM, Brazeau GA. Clinical pharmacology of the dietary supplement creatine monohydrate. Pharmacol Rev. 2001; 53(2):161-76.

10. Ellis AC, Rosenfeld J. The role of creatine in the management of amyotrophic lateral sclerosis and other neurodegenerative disorders. CNS Drugs. 2004; 18(14):967-80.

11. Halliwell B. Oxidative stress and neurodegeneration: where are we now? J Neurochem. 2006; 97(6): 1634-58.

12. Halliwell B. Reactive species and antioxidants. Redox biology is a fundamental theme of aerobic life. Plant Physiol. 2006; 141(2):312-22.

13. Bellinger BM, Bold A, Wilson GR, Noakes TD, Myburgh $\mathrm{KH}$. Oral creatine supplementation decreases plasma markers of adenine nucleotide degradation during a 1-h cycle test. Acta Physiol Scand. 2000; 170(3):217-24.

14. McConell GK, Shinewell J, Stephens TJ, Stathis CG, Canny BJ, Snow RJ. Creatine supplementation 
reduces muscle inosine monophosphate during endurance exercise in humans. Med Sci Sports Exerc. 2005; 37(12):2054-61.

15. Paddon-Jones D, Borsheim E, Wolfe RR. Potential ergogenic effects of arginine and creatine supplementation. J Nutr. 2004; 134(10 Suppl): 2888S-94S; discussion 2895 S.

16. Vergnani L, Hatrik S, Ricci F, Passaro A, Manzoli N, Zuliani $G$, et al. Effect of native and oxidized low-density lipoprotein on endothelial nitric oxide and superoxide production: key role of L-arginine availability. Circulation. 2000; 101(11):1261-6.
17. Lemon PW. Dietary creatine supplementation and exercise performance: why inconsistent results? Can J Appl Physiol. 2002; 27(6):663-81.

18. Derave W, Eijnde BO, Hespel P. Creatine supplementation in health and disease: what is the evidence for long-term efficacy? Mol Cell Biochem. 2003; 244(1-2):49-55.

Recebido em: 11/10/2006

Versão final reapresentada em: 20/7/2007

Aprovado em: 28/2/2008 